\title{
ESTUDOS ETNOBOTÂNICOS E AULAS SOBRE PLANTAS MEDICINAIS NA E.E. MARIA LUIZA DE GUIMARAES MEDEIROS, SÃO JOSÉ DOS CAMPOS - SP
}

\author{
Alefe T. Cordeiro Cavalcante ${ }^{1}$ \\ Ariane de Araujo Ferreira ${ }^{2}$ \\ Anelise Garcia Martins ${ }^{3}$ \\ Ida L. Mendes dos Santos ${ }^{4}$ \\ Laila C. da Cunha Freitas Santana ${ }^{5}$ \\ Monica C. Silva Souza Vicente ${ }^{6}$ \\ Sabrina Horschut Sandim ${ }^{7}$ \\ Walderez Moreira Joaquim ${ }^{8}$ \\ Karla Andressa Ruiz Lopes ${ }^{9}$ \\ Nadia Maria Campus Velho ${ }^{10}$ \\ Elisa Celeste Dreux ${ }^{11}$
}

Resumo: O presente trabalho objetivou investigar o conhecimento etnobotânico dos alunos da E. E. Maria Luiza de Guimarães Medeiros, localizado na região Norte de São José dos Campos - SP e paralelamente desenvolver aulas práticas com os alunos participantes do projeto PIBID, relacionadas ao uso de plantas medicinais. O trabalho foi realizado em duas etapas: (a) a primeira foi a aplicação de um questionário de etnobotânica sobre dados socioeconômicos, conhecimentos e uso sobre plantas medicinais que foram entregues aos alunos para que entrevistassem pessoas da comunidade a qual pertenciam; (b) a segunda etapa foi o desenvolvimento de atividades práticas sobre conceitos relacionados ao uso de planta medicinais. O estudo revelou que o conhecimento sobre o uso de plantas medicinais é praticado pelos moradores, principalmente pelas mulheres (70\%) e alunos que residem na região rural (50\%). Os bairros que compõem a região Norte vêm sofrendo descaracterização da cultura da região fator atribuído a implantação de casas populares, fato que pode ser notado no comportamento dos alunos e mudanças nos hábitos de cultivo e uso de plantas medicinais.

Palavras-chave: Botânica; Conhecimento popular; Ervas medicinais.

\footnotetext{
${ }^{1}$ Licenciando bolsista PIBID/CAPES/UNIVAP. E-mail: alefetales@hotmail.com.

2 Licencianda bolsista PIBID/CAPES/UNIVAP. E-mail: ariane.araujoferreira@gmail.com.

${ }^{3}$ Licencianda bolsista PIBID/CAPES/UNIVAP. E-mail: tecnico.ma.anelise@gmail.com.

${ }^{4}$ Licencianda bolsista PIBID/CAPES/UNIVAP. E-mail: idaleticiamendes.santos@gmail.com.

${ }^{5}$ Licencianda bolsista PIBID/CAPES/UNIVAP. E-mail: lailafsantana@hotmail.com.

${ }^{6}$ Licencianda bolsista PIBID/CAPES/UNIVAP. E-mail: mcmochristine@gmail.com.

7 Licencianda bolsista PIBID/CAPES/UNIVAP. E-mail: sabrinahsandim@hotmail.com.

${ }^{8}$ Coordenadora Subprojeto Biologia/PIBID/CAPES - SJCampos/SP, Brasil. E-mail: wal@univap.br.

${ }^{9}$ Coordenadora Subprojeto Biologia/PIBID/CAPES - SJCampos/SP, Brasil. E-mail: karla@univap.br.

${ }^{10}$ Coordenadora Subprojeto Biologia/PIBID/CAPES - SJCampos/SP, Brasil. E-mail: nvelho@univap.br.

11 Supervisora E.E. Maria Luísa de Guimarães Medeiros, São José dos Campos/SP-PIBID/CAPES, Brasil. E-mail: ecdreux@ig.com.br.
} 